\title{
Current Views on the Management of Incompetent Perforator Veins
}

\author{
Department of Surgery, Stony Brook Medicine, Newyork, USA \\ Nicos Labropoulos, Ph.D.
}

Chronic venous disease (CVD) is prevalent worldwide. Many patients suffer from signs and symptoms of CVD. The impact of superficial and deep vein disease is well established. However, the role of perforator veins is controversial (1-3). There are many randomized trials showing the effect of treatment on superficial veins mostly by ablation techniques, phlebectomies and sclerotherapy. There is an increasing body of evidence for treating deep vein obstruction but a definitive trial (CTRACT) is on its way (4). The purpose of this paper was to define the impact of perforator veins in patients with CVD.

\section{STRUCTURAL AND FUNCTIONAL CONSIDERATIONS}

The perforator veins pierce the deep fascia and connect the superficial veins with the deep axial and muscular veins. They may often have more than one connection with the deep veins. Most of the perforator veins have at least one valve located closer to the deep veins (5). Although some calf perforator veins allow inward (towards the deep veins) and outward (towards the superficial veins) flow most of the blood volume is directed inwards (2). There are about 150 perforator veins in each human lower extremity (60 in the thigh, 8 in popliteal fossa, 55 in the leg and 28 in the foot) as shown by van Limborgh in 1961 using micro injection techniques $(6,7)$. About 30 of them may become incompetent and may contribute into the venous hypertension (2). Most of the incompetent perforator veins are located in the calf. A perforator vein is accompanied by a perforating artery which is smaller in diameter than the vein and a nerve

Corresponding : Nicos Labropoulos, 101 Nicolls Road, Stony Brook, NY, USA

11794, Department of Surgery HSC T19-94, Stony Brook Medicine

Tel: 631-444-2019, Fax: 631-444-8988

E-mail: nlabrop@yahoo.com which is thinner that the artery.

It is believed that perforator veins are the cause of venous reflux and recurrent venous disease. This information is based on cross-sectional studies where function was examined at one time point without knowing the sequence of events. The volume in the perforating veins is small and reflux has been defined as outward flow of $>350 \mathrm{~ms}$ but for simplicity has been accepted as $>0.5 \mathrm{~s}$ similar to the superficial veins (8). However with time in patients having reflux more blood is going through the perforators to be drained in the deep veins. These perforator veins due to the higher volume of blood dilate over time to accommodate the need and at some point may become incompetent (9). Perforator veins develop also reflux by vein wall disease extension from the affected superficial veins that are connected to the perforators as demonstrated in a longitudinal study (9). In primary venous disease reflux in the perforator veins alone with normal superficial veins connecting with them has never been demonstrated. In all occasions when the perforator veins are incompetent the superficial veins that connect with them are also have reflux. This has important clinical implications.

Another issue has been the relevance of the perforator veins as cause of recurrent varicose veins. Most studies showing an association with this they have not provide a clear evidence. Even in the REVAS study which was prospective an association was demonstrated with recurrence but it was not demonstrated to be the cause (10). In REVAS and other studies incompetent perforators persist due to treatment failure or develop reflux as venous disease progresses $(1,10,11)$. In all papers published before and after treatment never has been demonstrated that reflux started in a perforator and then extended in the superficial veins.

\section{CLINICAL IMPACT}

The size and number of incompetent perforators increases with venous disease severity (2). Such veins are more common 
in patients with skin damage and particularly in those with ulcers and are most often found in the lower calf and ankle regions $(2,12)$. The guidelines are against treating perforating veins in patients with CEAP classes 0 to 3 (13-15). They suggest treatment of pathological perforator veins which are those having $>0.5 \mathrm{~s}$ reflux duration and $>3.5 \mathrm{~mm}$ in diameter and are found at or near the ulcer which is difficult to heal or when it recurs (12). The evidence for treating such perforators is weak, while there are no papers supporting treatment in patients with CEAP class 4 . Nevertheless, still many practitioners treat perforating veins even in the absence of skin damage.

A systematic review of 20 studies (1RCTand 19 case series) having 1140 treated limbs indicated that SEPS with or without saphenous ablation lead to an $88 \%$ chance for ulcer healing and $13 \%$ chance for recurrence at short term (16). They suggested that RCTs should be performed to demonstrate the effect of treating the perforating veins. Subsequently two RTs were performed and none showed a clear benefit from treating the perforating veins in patients with venous ulcers $(17,18)$. The first one was mostly designed to address conservative versus surgical treatment and added the SEPS in 51 limbs who had superficial surgery and in 40 limbs with previous superficial surgery (17). They suggested in the secondary end points benefit on ulcer free period but that is highly questionable as many things were not controlled and unequal comparisons were made. In the second RCT there was no short-term clinical benefit from adding SEPS to saphenous surgery in patients with venous ulcers and incompetent perforators, despite SEPS reducing the number of perforators at 1 year (18).

Thermal ablation of the perforator veins has an occlusion rate ranging from $60 \%$ to $80 \%$ (19). Closure rate may improve by retreating failures. Ultrasound guided foam sclerotherapy may have lesser closure rate compare to thermal ablation but it is easier to perform and also treat the varicose veins at and near the ulcer area. There may be some benefit in treating perforating veins in patients with venous ulcers as described above. However, prospective studies having enough power and good follow-up are needed.

\section{REFERENCES}

1) van Rij AM, Hill G, Gray C, Christie R, Macfarlane J, Thomson I. A prospective study of the fate of venous leg perforators after varicose vein surgery. J Vasc Surg 2005; 42:1156-62.
2) Labropoulos N, Mansour MA, Hang SS, Gloviczki P, Baker WH. New insights into perforator vein incompetence. Eur J Vasc Endovasc Surg 1999;18:228-34.

3) O'Donnell TF Jr. Part two: against the motion. Venous perforator surgery is unproven and does not reduce recurrences. Eur J Vasc Endovasc Surg 2014;48:242-6.

4) Chronic Venous Thrombosis: Relief With Adjunctive Catheter-Directed Therapy (The C-TRACT Trial) (C-TRACT). ClinicalTrials.gov Identifier: NCT03250247

5) Pirner F. Die Bedeutung der insuff. V. perforans fu" $r$ die Kramp fadeoperation. Chir Praxis 1963;7:112-119.

6) Limborgh J van. L'anatomie du syste'me veineux de l'extremite infe'rieure en relation avec la pathologie variqueuse. Folia Angiol 1961;8:240-257.

7) Limborgh J van. Anatomie der venae communicantes. Zbl Phlebol 1965;4:268-271.

8) Labropoulos N, Tiongson J, Pryor L, Tassiopoulos AK, Kang S, Mansour MA, et al. Definition of venous reflux in lower-extremity veins. J Vasc Surg 2003;38:793-8.

9) Labropoulos N, Tassiopoulos AK, Bhatti AF, Leon L. Development of reflux in the perforator veins in limbs with primary venous disease. J Vasc Surg 2006;43:558-62.

10) Perrin MR, Labropoulos N, Leon LR. Presentation of a patient with recurrent varices after surgery (REVAS). J Vasc Surg 2006;43:327-34.

11) Nelzén O, Fransson I. Varicose vein recurrence and patient satisfaction10-14 years following combined superficial and perforator vein surgery: a prospective case study. Eur J Vasc Endovasc Surg 2013;46:372-7.

12) Labropoulos N, Patel PJ, Tiongson JE, Pryor L, Leon LR Jr, Tassiopoulos AK. Patterns of venous reflux and obstruction in patients with skin damage due to chronic venous disease. Vasc Endovascular Surg 2007;41:33-40.

13) Gloviczki P, Comerota AJ, Dalsing MC, et al. The care of patients with varicose veins and associated chronic venous diseases: clinical practice guidelines of the Society for Vascular Surgery and the American Venous Forum. J Vasc Surg 2011;53:2S-48S.

14) Nicolaides A, Kakkos S, Eklof B, Perrin M, Nelzen O, Neglen P, Partsch H, Rybak Z. Management of chronic venous disorders of the lower limbs - guidelines according to scientific evidence. Int Angiol 2014;33:87-208.

15) Tenbrook JA Jr, Iafrati MD, O'donnell TF Jr, Wolf MP, Hoffman SN, Pauker SG, Lau J, Wong JB. Systematic review of outcomes after surgical management of venous disease incorporating subfascial endoscopic perforator surgery. J Vasc Surg 2004;39:583-9.

16) Wittens C, Davies AH, Bækgaard N, et al. Management of Chronic Venous Disease: Clinical Practice Guidelines of the European Society for Vascular Surgery. Eur J Vasc Endovasc Surg 2015;49:678-737.

17) van Gent WB, Hop WC, van Praag MC, Mackaay AJ, de 
Boer EM, Wittens CH. Conservative versus surgical treatment of venous leg ulcers: a prospective, randomized, multicenter trial. J Vasc Surg 2006;44:563-571.

18) Nelzén O, Fransson I; Swedish SEPS Study Group. Early results from a randomized trial of saphenous surgery with or without subfascial endoscopic perforator surgery in patients with a venous ulcer. Br J Surg 2011;98:495-500.

19) Dillavou ED, Harlander-Locke M, Labropoulos N, Elias S, Ozsvath KJ. Current state of the treatment of perforating veins. J Vasc Surg Venous Lymphat Disord 2016;4:131-5. 